\title{
Numerical Comparison of the Static Mechanical Behavior between ProFile GT and ProFile GT Series X Rotary Nickel-Titanium Files
}

\begin{abstract}
Introduction: This paper aims at evaluating how different superelastic nickel-titanium (NiTi) alloys determine the static mechanical performance of endodontic files during bending and torsion.

Methods: Two NiTi rotary instruments with similar geometries and equal cross-sections, a Profile $\mathrm{GT}^{\circledR}(\mathrm{GT})$ and a $\mathrm{GT}^{\circledR}$ Series $\mathrm{X}^{\mathrm{TM}}(\mathrm{GTX})$, were selected. The latter file is made from $\mathrm{M}$ Wire, a NiTi alloy that, according to its manufacturer, has been thermomecanically processed in order to have a larger flexibility at body temperature. The mechanical response was studied for a series of static bending and torsional loads using Finite Element (FE) models. The materials were characterized according to previously published stress-strain curves.

Results: For the same load and boundary conditions, the GTX material significantly increased the instrument's performance. For instance, the deflection for a $1 \mathrm{~N}$ force at the tip of the file was found to be $28.5 \%$ larger for the GTX file whereas the maximum stress decreased $13.2 \%$.

Conclusions: Although not fully reflective of the instrument's behavior in a dynamic rotation intra-canal system, the static results showed that the GTX file is more flexible and capable of stress relief at the most critical sections than the GT file, suggesting that it has a lower risk of fracture inside the root canals during its clinical use.
\end{abstract}

\section{Key Words}

NiTi; Rotary file; Endodontic instrument; M-Wire; GT files; GT series $\mathrm{X}$

\section{Introduction}

The emergence of nickel-titanium (NiTi) alloys and the development of their properties, namely superelasticity, motivated the inclusion of such materials in instruments that are used in the clinical practice of Endodontics, since instruments made from NiTi overcome the larger rigidity of stainless steel instruments (1). NiTi alloys have superior properties in ductility, fatigue, recoverable strain, biocompatibility and corrosion resistance (2). Flexibility in endodontic files is paramount for the preparation of anatomically complex root canals, since it preserves the dental structure, limits the apical transport, reduces the risk of iatrogenic 
mistakes and allows the irrigant to flow and reach the apical foramen $(3,4)$. However, when compared to common stainless steel instruments, the NiTi files present a higher risk of fracture inside the canal (5). Before introducing a stainless steel file into the root canal, one can check for visible signals of degradation (mostly by plastic deformation). These are trigger points to initiate fracture. On the contrary, in NiTi instruments, fracture usually occurs without visible signals of plastic deformation (6). This is one of the most important facts motivating the existing research around the subject (7).

Recent developments in endodontic files' design are mostly concerned with geometrical details, with emphasis on the cross-sectional design (8-10). However, the material properties have also deserved important developments. Ideally, a NiTi file should have excellent mechanical properties (measured by both the ultimate tensile strength and fatigue strength), it should be flexible enough to avoid canal puncture and damage, and its hardness should be large enough for a good cutting efficacy in the canal $(11,12)$.

Flexibility in NiTi files due to their superelastic behavior depends on the crystallographic phases in the material and on the thermic, mechanical and chemical treatments to which the alloy has been subjected to. In medical devices, the structure of the NiTi alloys at room temperature under no-load generally is austenitic. Martensite in NiTi alloys can be stress induced by a shear type of process, as it happens when deforming the rotary files while preparing the root canals. Since austenite is the stable phase at this temperature, the material springs back to its original shape when the stress is removed. These changes occur as a function of temperature and stress (11). There is an intermediate phase between the transformation is complete from austenite to martensite, called R-phase, first identified by Ling and Kaplow in 1981 (13). The R-phase has the advantage of having a much larger flexibility. This phase allows for a stress relaxation while deforming the endodontic instrument inside the root canal; thus, the loads will be much smaller than those needed to deform stainless steel instruments.

It has been observed that NiTi alloys usually allow a fully reversible deformation up to $8 \%$ strain, whereas stainless steels, by comparison, can only recover its original shape from strain values up to $0.2 \% \sim 0.5 \%(14,15)$.

The properties of rotary instrument files can be further enhanced through the use of thermic treatments and new manufacturing processes (16). Recently, the market has seen introduced the M-Wire ${ }^{\mathrm{TM}}$, a NiTi alloy used on the $\mathrm{GT}^{\circledR}$ series $\mathrm{X}^{\mathrm{TM}}$ (GTX) (Dentsply Tulsa Dental Specialties) files that, according to its manufacturer, has been thermomechanically processed in order to 
have a larger flexibility at body temperature (17). Peixoto et al. (18) compare the flexural fatigue and torsional resistance of GT and GTX instruments, taking into account their structural and dimensional characteristics, concluding that GTX instruments are more resistant to flexural fatigue than similar GT instruments made with conventional NiTi wire. With respect to torsional cyclic loading, they are in agreement with Kramkowski and Bahcall (19), that suggested that the GTX does not have an improved resistance to fracture. In what clinically relevant studies are concerned, Iqbal et al. (20) compare both instruments in apical transportation and length control in extracted mandibular molar teeth models, concluding that the newly designed GTX rotary instrument is as effective as the older ProFile GT instrument. To the extent of our knowledge, there is no other work yet that evaluates how M-Wire (used in the GTX file) improves the static mechanical performance of endodontic files when compared to conventional NiTi wire. The purpose of this study is to evaluate how different NiTi alloys determine the static mechanical performance of endodontic files during bending and torsion. Several simulations were computed with Finite Element (FE) modeling and analysis, using the same load and boundary conditions than those recently used in other reported works (8-10).

\section{Materials and methods}

Two commercial NiTi rotary files were selected for this study: ProFile $\mathrm{GT}^{\circledR} 20 / .06$ (GT) and $\mathrm{GT}^{\circledR}$ series X ${ }^{\mathrm{TM}}$ 20/.06 (GTX) (Dentsply Tulsa Dental Specialties).

A Mitutoyo PJ-A300 with QM Data 200 profile projector and a Leica Zoom 2000 microscope were used to assist in the geometrical characterization of both the GT and GTX files. They were modeled using SolidWorks ${ }^{\circledR} 2010$ (a 3D CAD $^{1}$ software) and ANSYS $^{\circledR} 12.1$ (a CAE $^{2}$ software). Both geometries tried to resemble the real files as much as possible, with larger pitch length and variable radial land widths along the GTX instrument's active part (figure 1). However, some approximations were made. First, the same concave ('U-shaped' flutes) cross-sections (8) were used in the models, due to the lack of detailed technical data available for the GTX instrument. Nevertheless, because both cross-sections are reported to be similar $(18,21)$, this approximation is expected to have a negligible effect in the model's bending stiffness (which depends on the cross-sectional area moment of inertia). Secondly, in order to reduce the

\footnotetext{
${ }^{1}$ CAD - Computer Aided Design.

${ }^{2} \mathrm{CAE}$ - Computer Aided Engineering.
} 
model complexity and computation time, the variable land widths were obtained progressively. This means that, although the model's tip region does not have narrow radial land widths, the mean (averaged) pitch length of the model is the same as in the real file, being increasingly similar from the tip to the shank (where the most resisting sections are). Despite all these approximations, the model is suitable for the purpose of this study. This is reinforced by Peixoto et al. (18), when they argue that the instruments performance cannot be attributed to differences in the geometry alone, being the mechanical properties of M-Wire the most important factor.

Tetrahedral structural solid elements (SOLID187) were used in the FE model. These are suited for complex geometries and for modeling irregular meshes (22). The multi-kinematic hardening plastic material model was selected in the software to approximate the stress-strain relationships of the NiTi alloys used in dentistry. For the general mechanical properties, a linear elastic isotropic material model was selected. This procedure is in agreement with (8). The files' material properties were modeled considering the stress-strain relationships from (23) (figure 1). The stress-strain relationship for conventional NiTi alloys used in dentistry - the one used in the GT rotary file - is similar to the one presented in (8), making it useful for comparison purposes. However, the stress-strain relationship for the NiTi alloy used in the GTX rotary file presents some differences, namely the smaller slope during the elastic austenitic phase (23.5 GPa against $40.1 \mathrm{GPa}$ ) and the smaller critical stress at the beginning of the phase transformation to R-phase (the pseudoelastic plateau, presenting a transformation value around $450 \mathrm{MPa}$ against $490 \mathrm{MPa}$ ). The Poisson's coefficient was considered 0.33 for both alloys (typical for many metallic alloys).

The mechanical behavior of the instruments was analyzed using the same load and boundary conditions as in $(8,9,10)$ (figure 1$)$ :

1) Evaluation of the von Mises ${ }^{3}$ stress distribution and tip deflection in bending. The instrument was clamped at the shaft cable and subjected to a static load of $1 \mathrm{~N}$ at its

3 The von Mises stress is the following combination of the six Cauchy stresses: $\sigma_{V M}=\sqrt{\frac{1}{2}\left[\left(\sigma_{x}-\sigma_{y}\right)^{2}+\left(\sigma_{x}-\sigma_{z}\right)^{2}+\left(\sigma_{y}-\sigma_{z}\right)^{2}+6\left(\tau_{x y}^{2}+\tau_{x z}^{2}+\tau_{y z}^{2}\right)\right]}$. The von Mises criterion establishes that, for ductile materials and for any state of stress, the plastic deformation occurs when the distortion energy reaches the same critical value as it reaches when in uniaxial tensile testing at the yield stress $\sigma_{c}$, i.e., when $\sigma_{V M}=\sigma_{c}$. 
tip. In a similar experiment, a bending displacement of $2 \mathrm{~mm}$ on the instrument's tip was simulated;

2) Evaluation of the von Mises stress distribution and shaft rotation in torsion. A torque of $2.5 \mathrm{Nmm}$ was applied at the edge of the shaft cable whilst the instrument was clamped $4 \mathrm{~mm}$ away from its tip. In a similar experiment, a $10^{\circ}$ clockwise rotation of the shaft cable was imposed.
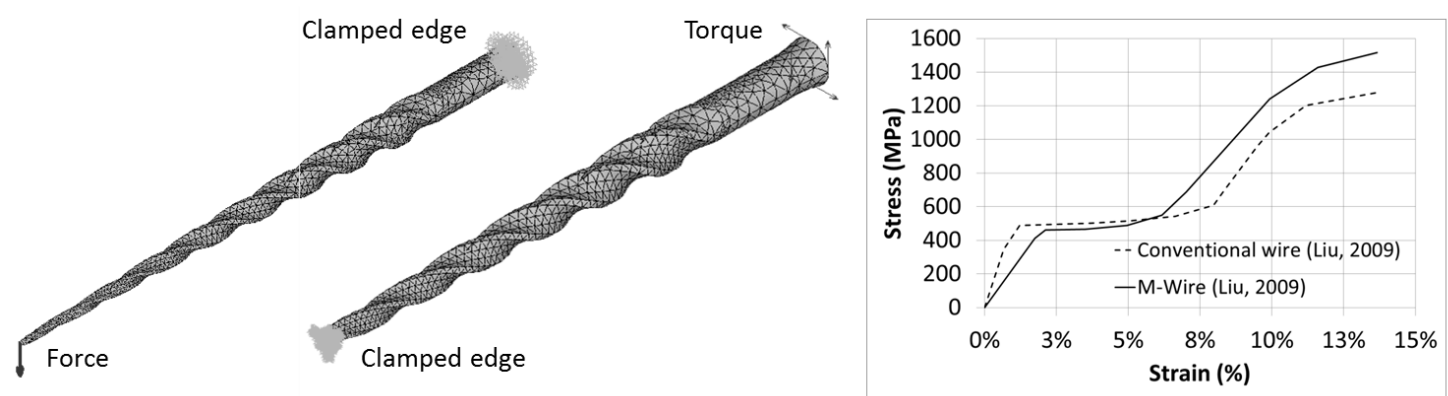

Figure 1. (A) uniaxial tensile stress-strain relations of conventional and M-Wire superelastic NiTi alloys (from (23). (B) GT and GTX CAD models and FE meshes with load and boundary conditions (GT case).

\section{Results}

Illustrative results of the von Mises distribution along the files are shown in figure 2. The load vs deformation relationships in both bending and torsion and a table summarizing the whole results are shown in figure 3. 

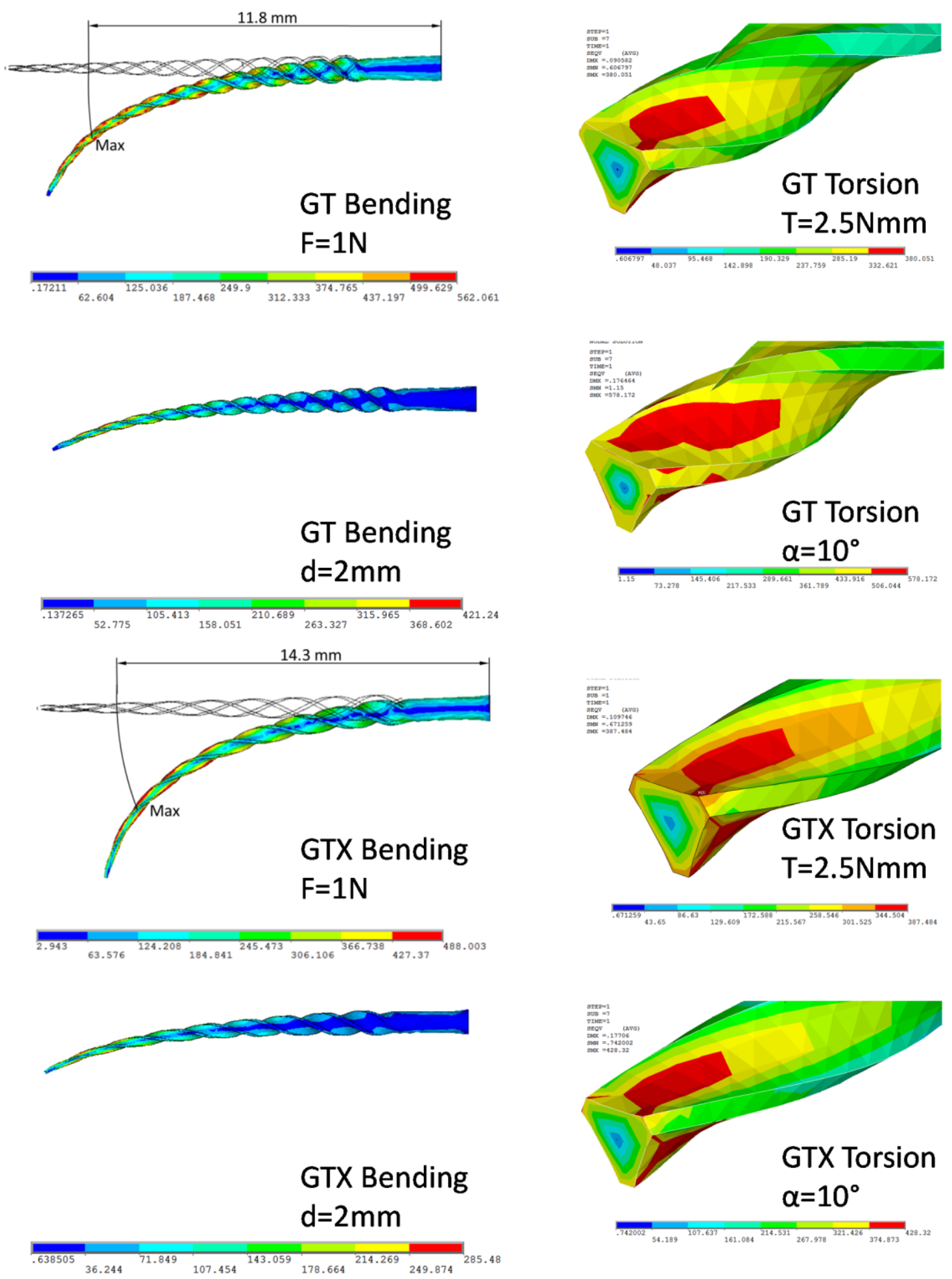

Figure 2. Stress distributions: (A) GT instrument under a $1 \mathrm{~N}$ tip force. (B) GT instrument under a $2 \mathrm{~mm}$ tip deflection. (C) GTX instrument under a $1 \mathrm{~N}$ tip force. (D) GTX instrument under a $2 \mathrm{~mm}$ tip deflection. (E) GT instrument under a $2.5 \mathrm{Nmm}$ torque. (F) GT instrument under a $10^{\circ}$ rotation angle. (G) GTX instrument under a $2.5 \mathrm{Nmm}$ torque. (H) GTX instrument under a $10^{\circ}$ rotation angle. 


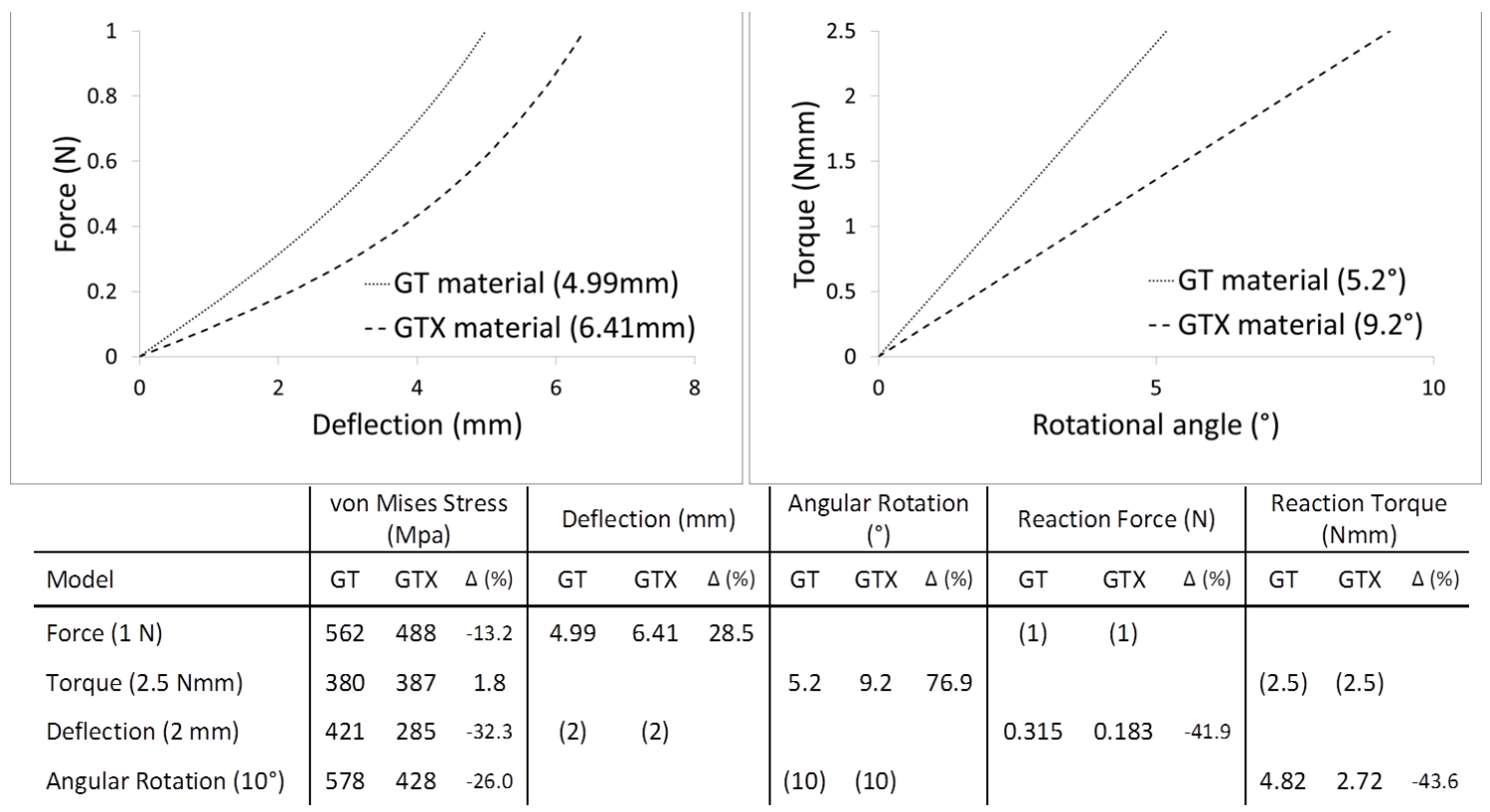

Figure 3. (A) Force vs deflection charts up to $1 \mathrm{~N}$ force. (B) Torque vs rotation charts up to $2.5 \mathrm{Nmm}$ torque. (C) Summary of the results.

\section{Discussion}

In this work, some FE models were tested in order to compare two endodontic rotary instruments, with emphasis on the material properties. Inside the root canals, the endodontic files are compelled to deform generating loads that mainly depend on the flexural and torsional stiffness of the instrument. Since the R-phase on NiTi superelastic alloys is very flexible (much smaller Young's modulus), then it can be said that this phase is very favorable, inducing local stress relaxations and a sudden decrease in the deformation reactive loads, which will not occur in files made from stainless steel. From the analysis of figures 2 and 3 the following is observed:

- For the same load and boundary conditions, the GT results (maximum stresses of $562 \mathrm{MPa}$ in bending and $380 \mathrm{MPa}$ in torsion) are coherent with those from other authors $(9,10)$ for ProFile instruments (maximum stresses of 577MPa in bending and 333MPa in torsion);

- Except for the $2.5 \mathrm{Nmm}$ torque case, the maximum stresses for the GTX file were smaller than for the GT (between -13\% and $-32 \%$ );

- For the same force ( $1 \mathrm{~N}$ at the tip) the GTX file was $28.5 \%$ more flexible than the GT file (6.4mm tip deflection against $5.0 \mathrm{~mm})$; 
- For the same torque ( $2.5 \mathrm{Nmm}$ at $4 \mathrm{~mm}$ from the tip) the GTX file was considerably more flexible than the GT file, with a twist practically twice as large $\left(9.2^{\circ}\right.$ against $5.2^{\circ}$ rotational angle);

- The force required for a $2 \mathrm{~mm}$ deflection of the GTX tip is practically half $(-42 \%)$ than the value needed for the same deflection of the GT tip;

- The torque needed for a $10^{\circ}$ rotational angle of the GTX file is practically half (-44\%) as much as the torque needed for the same rotation of the GT file;

- Both the force vs displacement file charts are non-linear, whereas the torque vs rotational angle charts behave linearly. This is not surprising; from the mechanics of materials, it is known that linearity only is observed for small deformations ${ }^{4}$ (torsional case). For large displacements, the load vs deformation relationship is known to be non-linear, even for simple beams. The GTX non-linear effect is highlighted because it deforms easily for smaller values of the force;

- It is important to notice that, under flexural or torsional loading, the instruments are subjected to heterogeneous stress distributions (marked by the color gradients on figure 2). As a consequence, different material crystallographic phases are present throughout the file's cross-sections. Taking the flexural case as an example, and neglecting torsional coupling (due to the complex geometry), some portions at the boundary of the files will be R-phase whereas those with a stress under the phase transformation (nearer to middle axis) will remain austenitic.

Additionally, note that there are considerable stress-strain differences in the martensitic region (figure 1) when comparing both materials. The GTX wire will plastically deform earlier than conventional $\mathrm{NiTi}$ (from $\sim 7 \%$ instead of $\sim 8 \%$ strain). Still, from this study and for the typical deformations found inside root canals during clinical practice (10), the stress levels are, in principle, far from plasticity in either file.

In summary, the GTX file, at body temperature and for the same static load and boundary conditions, showed to be more flexible and capable of stress relief at the most critical sections than the GT file. Nevertheless, it must be emphasized out that these results are not fully

\footnotetext{
${ }^{4}$ A small deformation might be understood when thinking of an arc in which its length may be approximated by a straight line. This may be done when the relationship $\sin (\alpha) \cong \alpha$, for $\alpha$ expressed in radians, is true.
} 
reflective of the instruments' properties in a dynamic rotation intra-canal system, but they represent a contribution to the understanding of their risk of fracture during clinical use.

\section{References}

1. Walia $\mathrm{H}$ and Brantley WA. An initial investigation of the bending and torsional properties of nitinol root canal files. J Endod, 1988; 14:346-51.

2. Wu SK. Multi-strengthening effects on the martensitic transformation temperatures of TiNi shape memory alloys. J Mater Sci, 1999; 34:5669-75.

3. Schäfer E and Oitzinger M. Cutting efficiency of five different types of rotary nickel titanium instruments. J Endod, 2008; 32:61-5.

4. Kell T, Azarpazhooh A, Peters OA, El-Mowafy, O, Tompson B and Basrani B. Torsional profiles of new and used 20/.06 GT series X and GT rotary endodontic instruments. J Endod, 2009; 35:1278-81.

5. Patiño V, Biedma BM, Liébana CR, Cantatore $G$ and Bahillo JG. The influence of manual glide path on the separation rate of Ni-Ti rotary instruments, J Endod, 2005; 31:114-6.

6. Martín B, Zelada G, Varela P, Bahillo JG, Magán F, Ahn S and Rodriguez C. Factors influencing the fracture of nickel-titanium rotary instruments. Int Endod J, 2003; 36:262-6.

7. Alçada FS. Characterization of GT and GT series $X$ profile system files by $X$-ray diffraction (MSc dissertation). Lisbon, Portugal: Faculdade de Medicina Dentária, University of Lisbon; 2010.

8. $\mathrm{Xu} X$, Eng $\mathrm{M}$, Zheng $\mathrm{Y}$ and Eng $\mathrm{D}$. Comparative study of torsional and bending properties for six models of nickel-titanium root canal instruments with different crosssections. J Endod, 2006; 32:372-5.

9. Kim TO, Cheung GSP, Lee JM, Kim BM, Hur B and Kim HC. Stress distribution of three $\mathrm{NiTi}$ rotary files under bending and torsional conditions using a mathematic analysis. Int Endod J, 2009; 42:14-21.

10. Kim HC, Kim HJ, Lee CJ, Kim BM, Park JK and Versluis A. Mechanical response of nickeltitanium instruments with different cross-sectional designs during shaping of simulated curved canals. Int Endod J, 2009; 42:593-602.

11. Thompson SA. An overview of nickel-titanium alloys used in dentistry. Int Endod J, 2000; 33:297-310. 
12. Liu J, Alapati S, Brantley WA, Clark W and lijima M. Vickers hardness study of clinically used M-Wire rotary endodontic instruments. J Dent Res, 2009; 88 (IADR Abstracts): Abstract No. 2854.

13. Ling HC and Kaplow R. Physical metallurgy of Ti-Ni-based shape memory alloys. Metall Trans, 1981; 12A:2101-11.

14. McKelvey AL and Ritchie RO. Fatigue-crack propagation in Nitinol, a shape-memory and superelastic endovascular stent material. J Biomed Mater Res, 1999; 47:301-8.

15. Rasmussen KJR. Full-range stress-strain curves for stainless steel alloys (report). University of Sydney, 2001; report no. R811.

16. Gambarini G, Gerosa R, Luca M, Garala M and Testarelli L. Mechanical properties of a new and improved nickel-titanium alloy for endodontic use: an evaluation of file flexibility. Oral Surg Oral Med Oral Pathol Oral Radiol Endod, 2008; 105:798-800.

17. Alapati SB, Brantley WA, lijima M, Clark WAT, Phil D, Kovarik L, Buie C, Liu J, Johnson WB. Metallurgical characterization of a new nickel-titanium wire for rotary endodontic instruments. J Endod, 2009; 35:1589-93.

18. Peixoto IFC, Pereira ES, Silva JG, Viana AC, Buono VT, Bahia MG. Flexural fatigue and torsional resistance of ProFile GT and ProFile GT series X instruments. J Endod, 2010; 36:74144.

19. Kramkowski TR, Bahcall J. An in vitro comparison of torsional stress and cyclic fatigue resistance of profile GT and profile GT series X rotary nickel-titanium files. J Endod, 2010; 35:404-7.

20. Iqbal MK, Floratos S, Hsu YK, Karabucak B. An in vitro comparison of ProFile GT and GTX nickel-titanium rotary instruments in apical transportation and length control in mandibular molar. J Endod, 2010; 36:302-4.

21. Lampert CJ. The GTX Rotary System. Roots, 2010; 2:28-9.

22. $\quad$ ANSYS $^{\circledR} 11$ elements reference manual; 2007.

23. Liu J. Characterization of new rotary endodontic instruments fabricated from special thermomechanically processed NiTi wire (PhD dissertation). Columbus, $\mathrm{OH}$ : The Ohio State University; 2009. 